\title{
Evaluating Two Assessment Methods for Gulf of Maine Northern Shrimp Based on Simulations
}

\author{
Steven X. Cadrin \\ National Marine Fisheries Service, Northeast Fisheries Science Center \\ 166 Water Street, Woods Hole, MA, USA
}

\begin{abstract}
Analyses of simulated data with measurement errors, process errors, and model specification errors similar to those for the fishery for Gulf of Maine northern shrimp, Pandalus borealis, demonstrate that a stage-based model (catch-survey analysis) provides accurate estimates of stock abundance, and that a surplus production model (ASPIC: a stock production model incorporating covariates) indicates accurate trends in stock biomass when catch and relative stock size indices are measured with moderate to high precision. However, the accuracy of catchsurvey estimates decreases when the precision of input data is low (i.e. greater than $30 \%$ coefficient of variation). Results suggest that catch-survey analysis of data with a wide range of observations is more reliable than those with a restricted range. Despite bias in estimates of stock biomass from ASPIC, trends in stock size are generally accurate.
\end{abstract}

Key words: abundance, assessment, Gulf of Maine, modelling, shrimp, simulation

\section{Introduction}

Lacking precise information on age and growth, some stock assessments of northern shrimp, Pandalus borealis, in the Northwest Atlantic have been based on models that use partial- or non-age based methods. Modal analyses of length distributions have had limited success in assessing the status of northern shrimp stocks because of interannual variability in recruitment and growth (Hvingel and Savard, 1997). The most common alternatives to age-based or length-based assessment techniques are biomass dynamics models (e.g. Graham, 1935; Schaefer, 1954; Pella and Tomlinson, 1969) and stage-based methods (e.g. Collie and Sissenwine, 1983; Schnute, 1987). Biomass dynamics models, commonly referred to as surplus production analyses, have been applied to northern shrimp fisheries off Iceland (Skúladóttir, 1979), in the Denmark Strait (Skúladóttir, MS 1985; Cadrin and Skúladóttir, MS 1998), in the Gulf of Maine (Cadrin et al., MS 1998, 1999) and off West Greenland (Hvingel and Kingsley, 1998). Stagebased models incorporate information on recruitment, usually defined by a size range of shrimp that will recruit to the fishery, and have been used to assess northern shrimp stocks off Iceland (Stefánsson et al., 1994) and in the Gulf of Maine (Cadrin et al., MS 1998, MS 1999).

When stock size is modeled as a forward projection through an observed time series, biomass dynamics methods (e.g. ASPIC: a stock production model incorporating covariates; Prager, 1994) and stagebased methods (e.g. catch-survey, or $\mathrm{C}-\mathrm{S}$, model; Collie and Sissenwine, 1983) scale stock size indices according to their response to fishery removals by minimizing observation errors from an assumed population dynamics process. However, both approaches can provide biased stock size estimates if survey catchability is poorly estimated. For example, ASPIC estimates of stock biomass for longfin inshore squid (Loligo pealeii) are less than area-swept biomass estimates from research surveys (Cadrin and Hatfield, MS 1999). Similarly, C-S estimates of abundance for surf clams (Spisula solidissima; NEFSC, MS 1996) and sea scallops (Placopecten magellanicus; NEFSC, MS 1997) were also less than survey-based estimates. In these cases, either the implied survey catchability is greater than one (which is unlikely), or survey catchabilities were overestimated by the model.

Simulation studies have been used to assess precision and bias of model estimates from $\mathrm{C}-\mathrm{S}$ and ASPIC. Prager et al. (1996) simulated age structured data for "swordfish-like" (Xiphias gladius) stocks and found that ASPIC generally provided reliable information on relative stock status despite measurement error and model specification error. However, ASPIC analyses of other simulated data sets revealed that production models require a time series of catch and biomass indices with a relatively wide 
range of observations (NRC, 1998; Prager 1998). Collie and Kruse (1998) simulated "king crab-like" (Paralithodes camtschatica) data and found that the $\mathrm{C}-\mathrm{S}$ model performed well with moderate measurement errors, but results were sensitive to some assumed population dynamics parameters in the process equation. Breen and Kendrick (1998) evaluated surplus production analysis of a spiny lobster (Jasus edwardsii) fishery by simulating data with similar characteristics as well as systematic errors. They concluded that the method was a useful tool if errors in input data were not too severe. However, simulations are generally performed to emulate certain data sets, and conclusions are therefore difficult to generalize for other applications with different data characteristics (Breen and Kendrick, 1998).

The objective of this study was to evaluate the accuracy of ASPIC and C-S results for data sets with similar characteristics to the Gulf of Maine shrimp population and fishery under various assumptions about measurement error, process error, and model specification error. Measurement error is defined as the difference between a sample estimate and the true value (e.g. the difference between an estimate of catch and the actual catch), process error is the difference between the estimated population response and the true population response (e.g. the difference between the change in abundance expected from a model and the actual change), and specification error is the difference between the population dynamics model and the true population dynamics (e.g. the difference between logistic growth and actual population behavior). The performance of analyses under simulated situations should help in understanding the limitations of the approaches and their relative merits for assessing the Gulf of Maine northern shrimp stock.

\section{Methods}

\section{C-S stage-based model}

The method described by Collie and Sissenwine (1983) was used to estimate abundance of two size classes: recruits $(R)$ and fully recruited shrimp $(N)$. The model fits a time series of catch and relative abundance indices of the two size classes of shrimp to a simple process equation:

$$
N_{t+1}=\left[\left(N_{t}+R_{t}\right) e^{-0.5 M}-C_{t}\right] e^{-0.5 M}
$$

where $t$ is an annual fishing season, recruited northern shrimp $\left(N_{t}+R_{t}\right.$, fully recruited plus new recruits to the fishery) experience a half-year of natural mortality $\left(e^{-0.5 M}\right)$, catch $(C$, in numbers) is removed at mid-year, and survivors from the fishery $\left[\left(N_{t}+R_{t}\right) e^{-0.5 M}-C_{t}\right]$ experience another half-year of natural mortality. Abundance is related to indices of relative abundance:

$$
n_{t}=q_{n} N_{t} e^{\eta t}
$$

and

$$
r_{t}=q_{r} R_{t} e^{\delta t}
$$

where $r_{t}$ and $n_{t}$ are observed survey indices of recruits and fully-recruited northern shrimp, $q$ is catchability of the survey gear, and $e^{\eta t}$ and $e^{\delta t}$ are lognormally distributed measurement errors. The process equation is derived by substituting survey indices into equation 3 and including lognormally distributed process error $\left(e^{\epsilon t}\right)$ :

$$
n_{t+1}=\left[\left(n_{t}+r_{t} / s_{r}\right) e^{-0.5 M}-q_{n} C_{t}\right] e^{-0.5 M} e^{\epsilon t}
$$

where

$$
s_{r}=q_{r} / q_{n}
$$

Observation and process errors are minimized by iteratively solving for $n_{t}, r_{t}$, and $q_{n}$. As assumed for Gulf of Maine shrimp, $M$ was assumed to be 0.25 , and $s_{r}$ was assumed to be 0.9 .

\section{ASPIC}

In comparison to other production models, ASPIC has the desirable features of being a time series method (Hilborn and Walters, 1992), an observation error estimator (Polachek et al., 1993), and is conditioned on catch (i.e. catch is assumed to be measured without error, and observation errors are in fishing effort or biomass indices rather than catch; Xiao, 1997). The model assumes logistic population growth, in which the change in stock biomass over time $\left(d B_{t} / d t\right)$ is a quadratic function of biomass $(B)$ and yield by the fishery $(Y$, in mass):

$$
d B_{t} / d t=r B_{t}\left(1-B_{t} / K\right)-Y_{t}
$$

where population growth is the intrinsic rate of increase, $r$, reduced as the stock size approaches its carrying capacity, $K$. Relative biomass indices from either research surveys or catch-per-unit-effort (CPUE) of a fishing fleet are used to calibrate the predicted biomass trajectory. Stock biomass is related to indices of relative biomass:

$$
b_{t}=q B_{t} e^{\beta t}
$$


where $b_{t}$ is an observed index of biomass, $q$ is the catchability of the index, and $e^{\beta t}$ is a lognormally distributed measurement error. The sum of squared measurement errors are minimized by iteratively solving for values of $r, K$, and $q$, and biomass in the first year.

\section{Simulations}

To emulate observation errors of the Gulf of Maine northern shrimp stock and fishery, "true" abundance of recruits and fully recruited shrimp, total biomass, and catch were taken directly from the most recent stock assessment for Gulf of Maine shrimp (1984-98; Clark et al.; 2000). Twenty sets of observed abundance and biomass indices were generated by randomly sampling lognormally distributed measure-ment errors assuming a $10 \%$ coefficient of variation (CV) which is appropriate for the Gulf of Maine shrimp survey (Cadrin et al., MS 1998, 1999). Appendix I describes the algorithm used to simulate observation errors.

A fifteen-year time series of survey indices and catches for shrimp-like fisheries was generated using the Collie-Sissenwine process equation (equation 6) with random errors in $M$ and $s_{r}$ to simulate process errors. A time series of observed catch and survey indices was generated with a series of different precisions $(10 \%, 20 \%, 30 \%, 40 \%$ and $50 \% \mathrm{CV})$. Appendix I describes the algorithm used to simulate process errors for $\mathrm{C}-\mathrm{S}$ analysis.

For surplus production analyses, 30-year time series of survey indices and catches were generated using the logistic growth equation with random errors in the parameters $r$ and $K$ to simulate process errors. Appendix I describes the algorithm used to simulate observation errors for ASPIC analysis.

Unlike simulated data with observation or process error, which were produced by the same model used to analyze the data (i.e. C-S or logistic growth), model specification error was simulated with a different model. Survey indices and catches were generated using a density-dependent, age-structured model based on a dynamic pool model of Gulf of Maine northern shrimp (Cadrin et al., 1999). Appendix I describes the algorithm used to simulate specification errors.

Relative performance of methods was evaluated using relative root mean square error between estimates and true values from simulations. Bias was tested using a $t$-ratio test (Sokal and Rohlf, 1995).

\section{Results}

Catch-Survey analysis of data with simulated observation error, similar to that reported for the Gulf of Maine shrimp assessment generated a range of stock sizes around the "true" population values (Fig. 1). Surplus production analysis of data with observation errors provided similar results, with substantially wider ranges of estimates in the first four to five years, confirming that ASPIC biomass estimates from the first several years are the least reliable (Prager, MS 1995; Fig. 2).

Catch-Survey analyses of data with simulated observation and process error shows that accuracy of stock size estimates and relative trends in stock size increase with greater precision of input data (Table 1; Fig. 3). At $10 \% \mathrm{CV}$ in catch and survey indices (Fig. 3a) all abundance estimates were relatively accurate (i.e. within $10 \%$ of the "true" value). At $20 \%$ $\mathrm{CV}$ in catch and survey indices, estimates of abundance were frequently inaccurate (e.g. average relative errors were $>10 \%$ for $50 \%$ of simulations, and $>25 \%$ for $13 \%$ of simulations), however all relative trends were accurate. At $30 \% \mathrm{CV}$ in input data, relative errors were similar, but some relative trends in estimates were misleading. At $40 \% \mathrm{CV}$ in input data, relative errors in abundance estimates were frequently greater than $50 \%$, and relative trends were misleading for many simulations (Fig. 3b). At lower levels of precision (i.e. CV $>20 \%$ ), most of the inaccurate abundance estimates were from simulations with narrow ranges of survey observations (Fig. 4). For example, all simulations with an average relative error greater than $30 \%$ had a relatively restricted range of observed abundance indices ( $\mathrm{CV}<35 \%$ ), whereas all simulations with a broader range of indices had relative errors of $20 \%$ or less. Estimates of bias were

TABLE 1. Relative error (root mean square error/true value) in estimates of survey catchability $(q)$, fully-recruited abundance $(N)$, and recruit abundance $(R)$ from Catch-Survey analysis of simulated shrimp-like data at various levels of observation and process error $(10 \%, 20 \%, 30 \%$ and $40 \%$ coefficient of variation, $\mathrm{CV}$ ).

\begin{tabular}{lccc}
\hline \hline CV & $q$ & $N$ & $R$ \\
\hline $10 \%$ & 0.09 & 0.08 & 0.06 \\
$20 \%$ & 0.12 & 0.15 & 0.12 \\
$30 \%$ & 0.19 & 0.25 & 0.16 \\
$40 \%$ & 0.20 & 0.35 & 0.25 \\
\hline
\end{tabular}



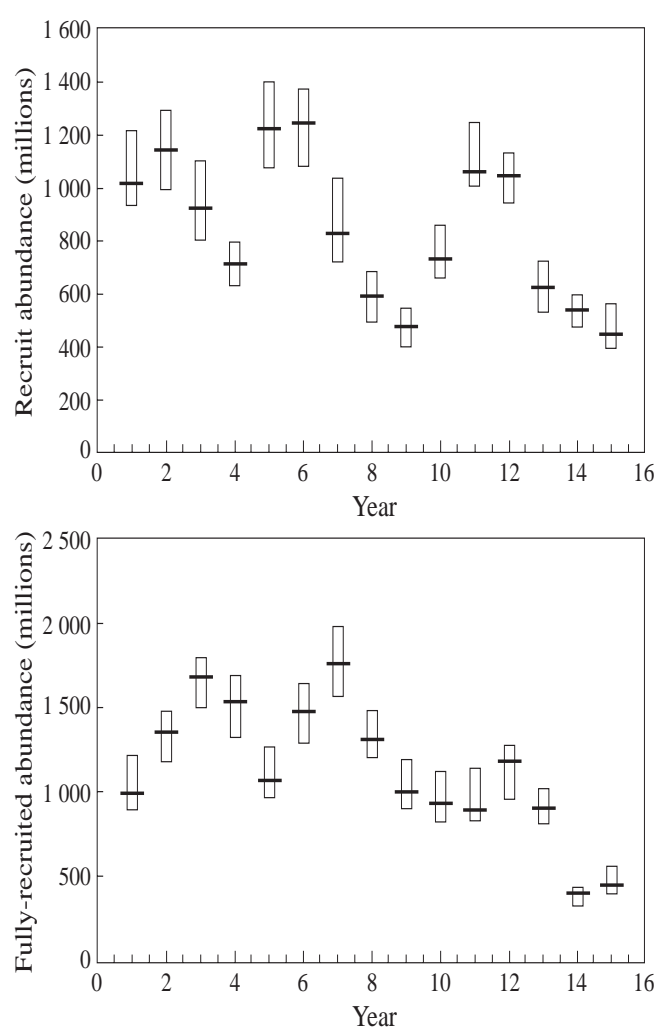

Fig. 1. True values (horizontal lines) and distribution of Catch-Survey estimates (boxes indicate $80 \%$ confidence intervals) of recruit abundance (above) and fully-recruited abundance (below) based on simulated data with $10 \%$ observation error and similar characteristics as Gulf of Maine shrimp.

not significant and were inconsistent among different levels of variance (i.e. bias was slightly positive at $10 \%$ $\mathrm{CV}$, slightly negative at $20 \% \mathrm{CV}$, slightly positive at $30 \% \mathrm{CV}$, and slightly negative at $40 \% \mathrm{CV}$ ).

Surplus production analysis of data with simulated observation and process error were only moderately accurate. The relative error of biomass estimates was $25 \%$, and $20 \%$ of trials had greater than $50 \%$ relative error from analysis of data with $10 \%$ observation and process error (Fig. 5). Analysis of simulated data with greater levels of error (e.g. $\mathrm{CV}=20 \%, 30 \%$, and $40 \%$ ) had frequent problems with convergence.

Catch-Survey analysis of data with simulated specification error produced relatively precise and unbiased abundance estimates (Fig. 6). Relative errors of abundance estimates averaged $14 \%$ when $10 \%$ observation error was simulated. However, ASPIC estimates of biomass from data with simulated specification error were significantly biased low (Fig.

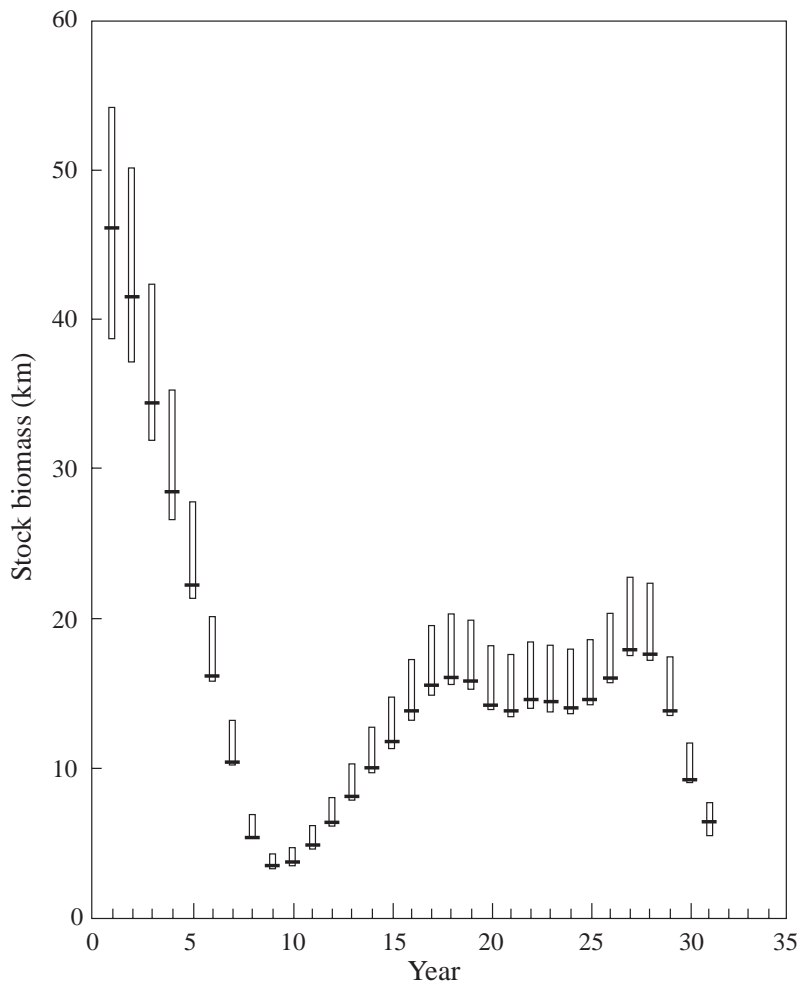

Fig. 2. True values (horizontal lines) and distribution of ASPIC estimates (boxes indicate $80 \%$ confidence intervals) of stock biomass based on simulated data with $10 \%$ observation error and similar characteristics as Gulf of Maine shrimp.

7). Despite unreliable estimates of catchability, trends in biomass from ASPIC were accurate.

\section{Discussion}

Although results from analyses of data with simulated observation error seem trivial because the same model and parameters were used to simulate the data, they serve as a Monte Carlo estimate of variance (Manly, 1997) and are similar to reported variance estimates from bootstrap analyses (Cadrin et al., 1999). The comparison serves as a reminder that conventional estimates of variance from asymptotic theory, jackknifing (Hvingel and Kingsley, MS 1998), or bootstrapping (Cadrin et al., 1999) only encompass observation error and do not include other sources of uncertainty.

Inaccurate abundance estimates from data with low precision highlights the need to routinely evaluate the variance of catch and survey biomass estimates. Precision of catch and survey abundance estimates for Gulf of Maine shrimp is approximately $10 \% \mathrm{CV}$. 

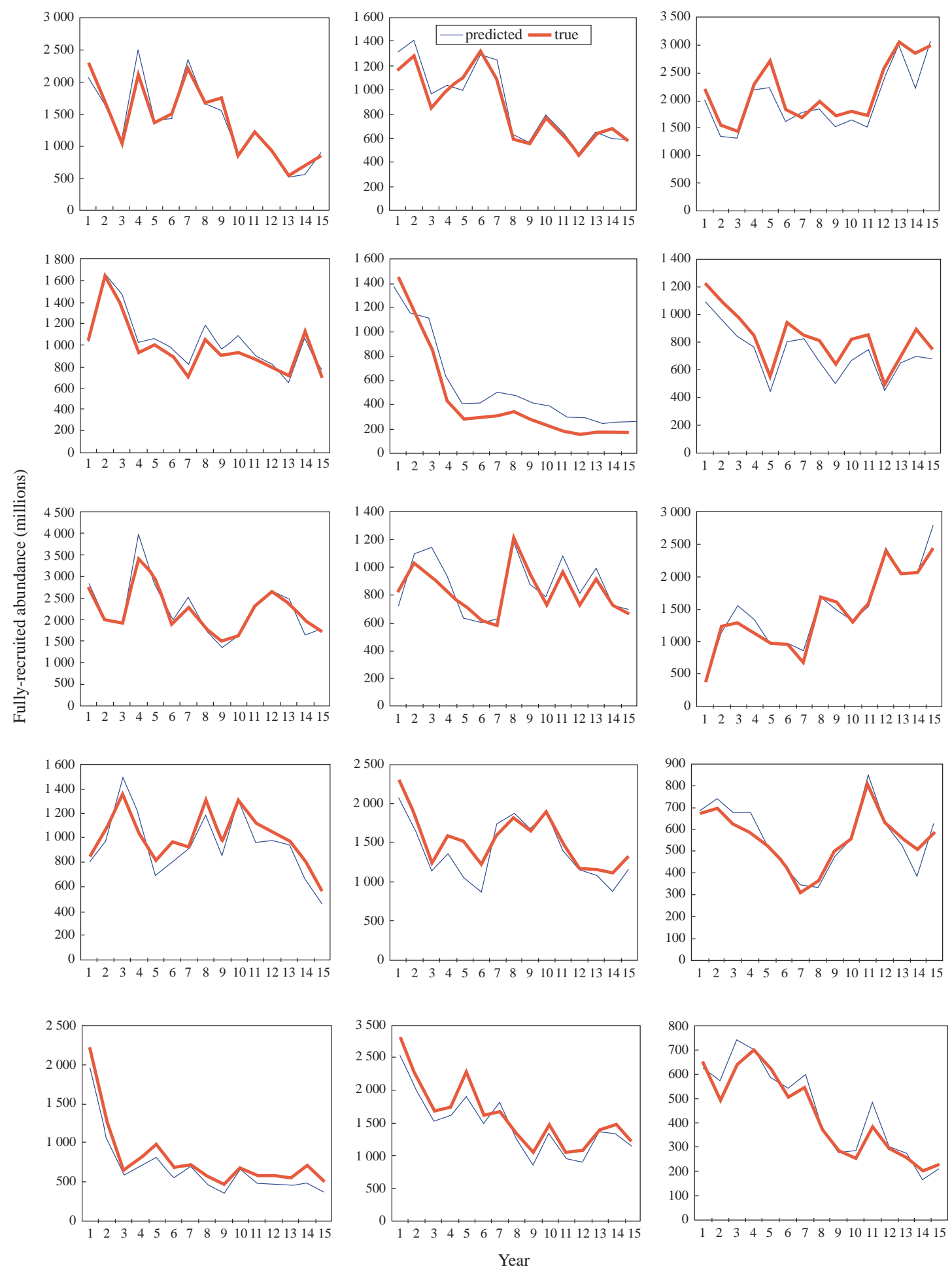

Fig. 3a. True values and Catch-Survey estimates of fully-recruited abundance based on simulated shrimp-like data with $10 \%$ observation and process error. Each panel represents a different simulation.

Simulations with lower precision of both fishery catch and survey data were conducted for illustrative purposes, but the two sources of input data are independent. Results of analyses that use different levels of observation and process error are somewhat consistent with those from simulated king crab data 

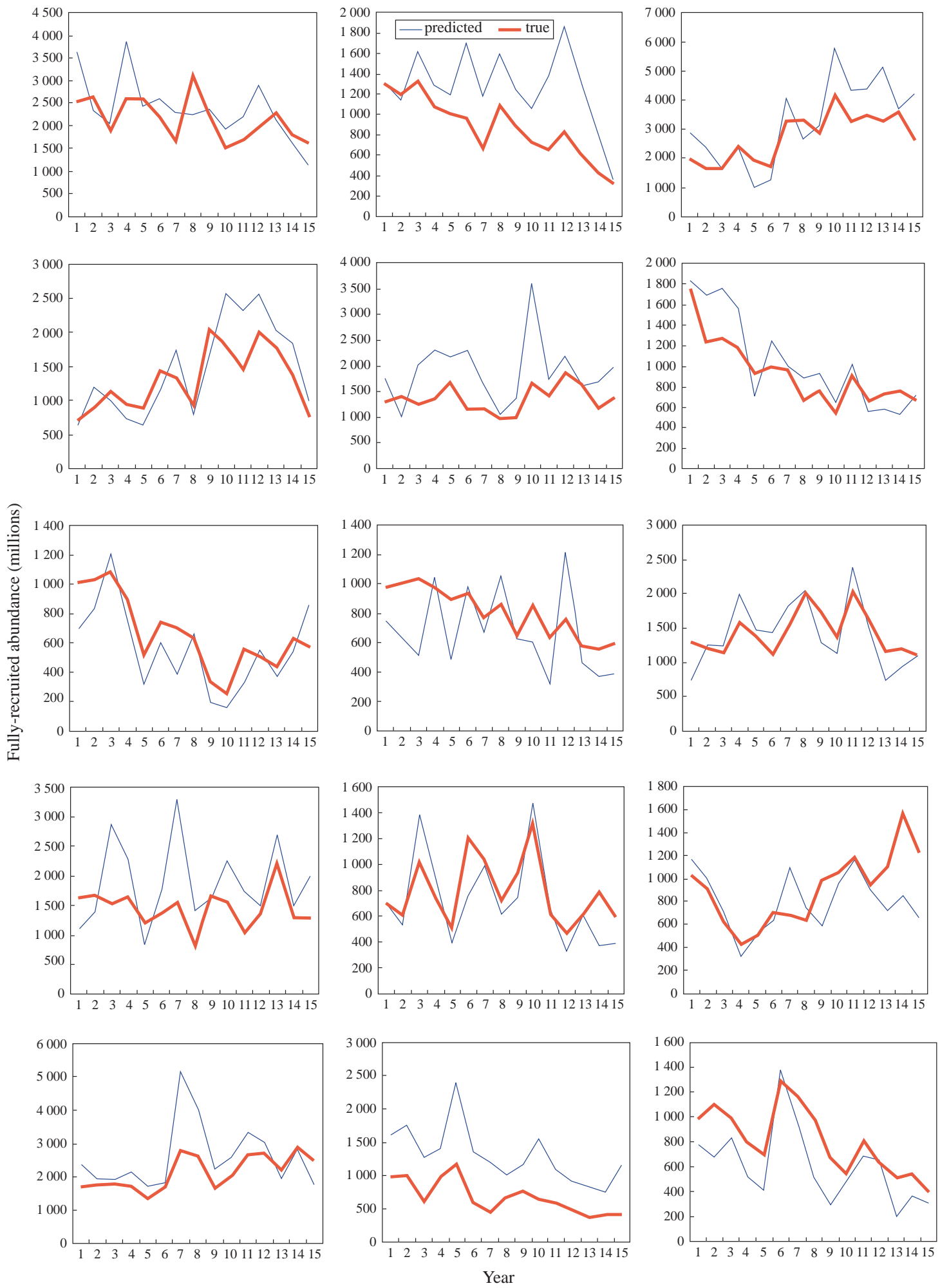

Fig. 3b. True values and Catch-Survey estimates of fully-recruited abundance based on simulated shrimp-like data with $40 \%$ observation and process error. Each panel represents a different simulation. 


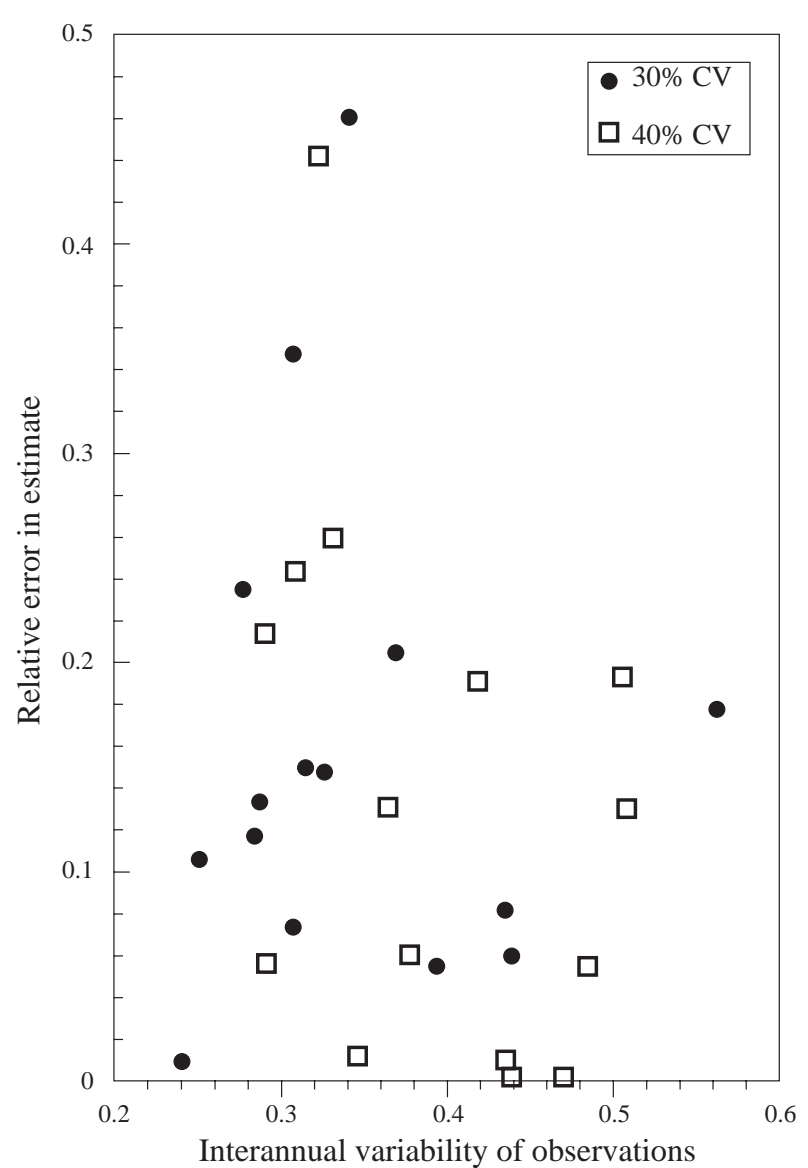

Fig. 4. Relative error in Catch-Survey estimates of catchability (root mean square error/true value) and interannual variability of survey indices of fully-recruited shrimp at two levels of observation and process error $(30 \% \mathrm{CV}$, solid squares, and $40 \%$ $\mathrm{CV}$, open squares).

in that relative error of estimates increases at greater levels of input error (Collie and Kruse, 1998). However, the present results do not indicate an increase in bias as observation and process error increase. Similar to surplus production models (Hilborn and Walters, 1992; Prager et al., 1996), estimates from $\mathrm{C}-\mathrm{S}$ are more reliable when input data have a wide range of contrast. Although the negative relationship between inaccuracy of results and dynamic range of input data is not strong (Fig. 4), the pattern suggests that $\mathrm{C}-\mathrm{S}$ analyses of data with a wide range of observations are more reliable than those having a restricted range of observations.

Moderate inaccuracies in estimates of stock biomass from surplus production models of data with simulated process error are consistent with results from other studies (Breen and Kendrick, 1998, Ludwig et al., 1988). The present results confirm that estimates of $q$ from ASPIC can be unreliable, but despite this problem, trends in biomass may be accurate (Prager, 1994). Biases in ASPIC estimates from data with specification error probably result from the age-based population dynamics model not conforming to logistic growth. However, some components of the age-based simulations (e.g. stockrecruit data) are based on very limited information and may not accurately reflect the dynamics of Gulf of Maine northern shrimp. In a comparison of the performance of several stock assessment techniques on simulated data, it was concluded that the types of data and assumptions made in simulations can skew results in favor of one model over another (NRC, 1998).

Specification error does not appear to be a problem with $\mathrm{C}-\mathrm{S}$, presumably because the underlying process equation is empirical, not theoretical (i.e. recruitment is observed rather than implicitly predicted from a population growth model). Application of $\mathrm{C}-\mathrm{S}$ to the Gulf of Maine shrimp fishery appears to be insensitive to interannual variability in length at age, transition at age, and selectivity at age. Although the $\mathrm{C}-\mathrm{S}$ process equation may be robust to different population dynamics, $\mathrm{C}-\mathrm{S}$ results are sensitive to incorrect model assumptions (e.g. natural mortality, length selectivity of the fishery, relative survey catchability of recruits and recruited shrimp; Conser and Idoine, MS 1992; Collie and Kruse, 1998). Perhaps the most important assumption is that recruit and fully-recruited size classes are correctly defined.

The present study simulated imprecision in assumed $\mathrm{C}-\mathrm{S}$ process parameters (i.e. random variation from the true value), but did not simulate inaccurate assumptions (i.e. bias in process parameters). Simulation can be used to assess a variety of specific concerns about model assumptions, such as autocorrelated process error (Sissenwine, 1977), different forms of production curves (Sissenwine, 1977; Breen and Kendrick, 1998), temporal changes in selectivity (Prager et al., 1996), and different survey catchabilities of $R$ and $N$ (Collie and Kruse, 1998).

Analyses of data that simulate the approximate levels of process and observation errors for the Gulf of Maine northern shrimp stock indicate that abundance estimates from the $\mathrm{C}-\mathrm{S}$ model and relative trends in biomass from ASPIC are relatively accurate. The results may not apply to all applications of either $\mathrm{C}-\mathrm{S}$ or ASPIC, because they are conditional on the specifics of the simulation methods (e.g. number of years, level of $F$, assumed levels of precision). Therefore, analysis of simulated data, which emulates 

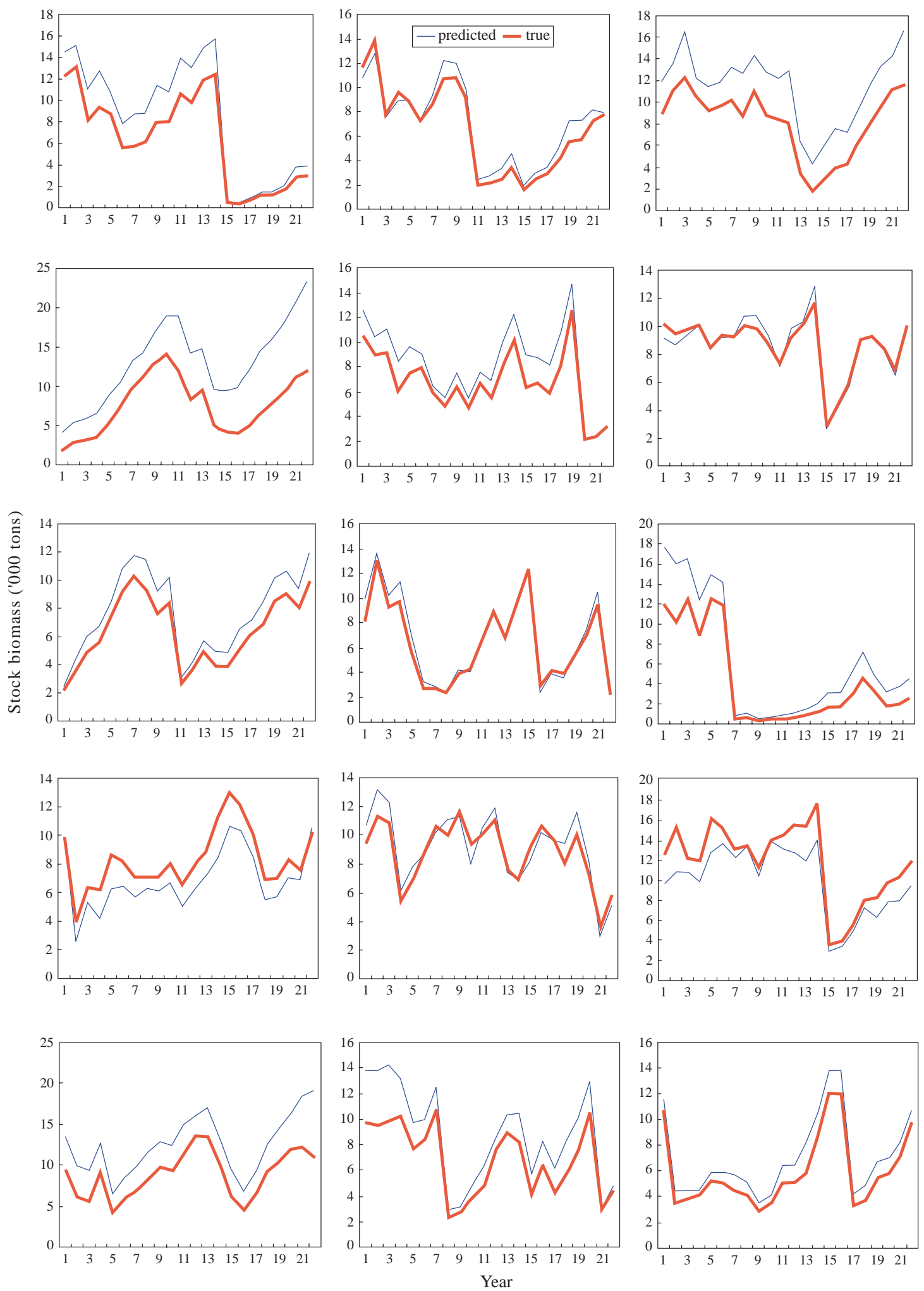

Fig. 5. True values and ASPIC estimates of stock biomass based on simulated shrimp-like data with $10 \%$ observation and process error. Each panel represents a different simulation. 

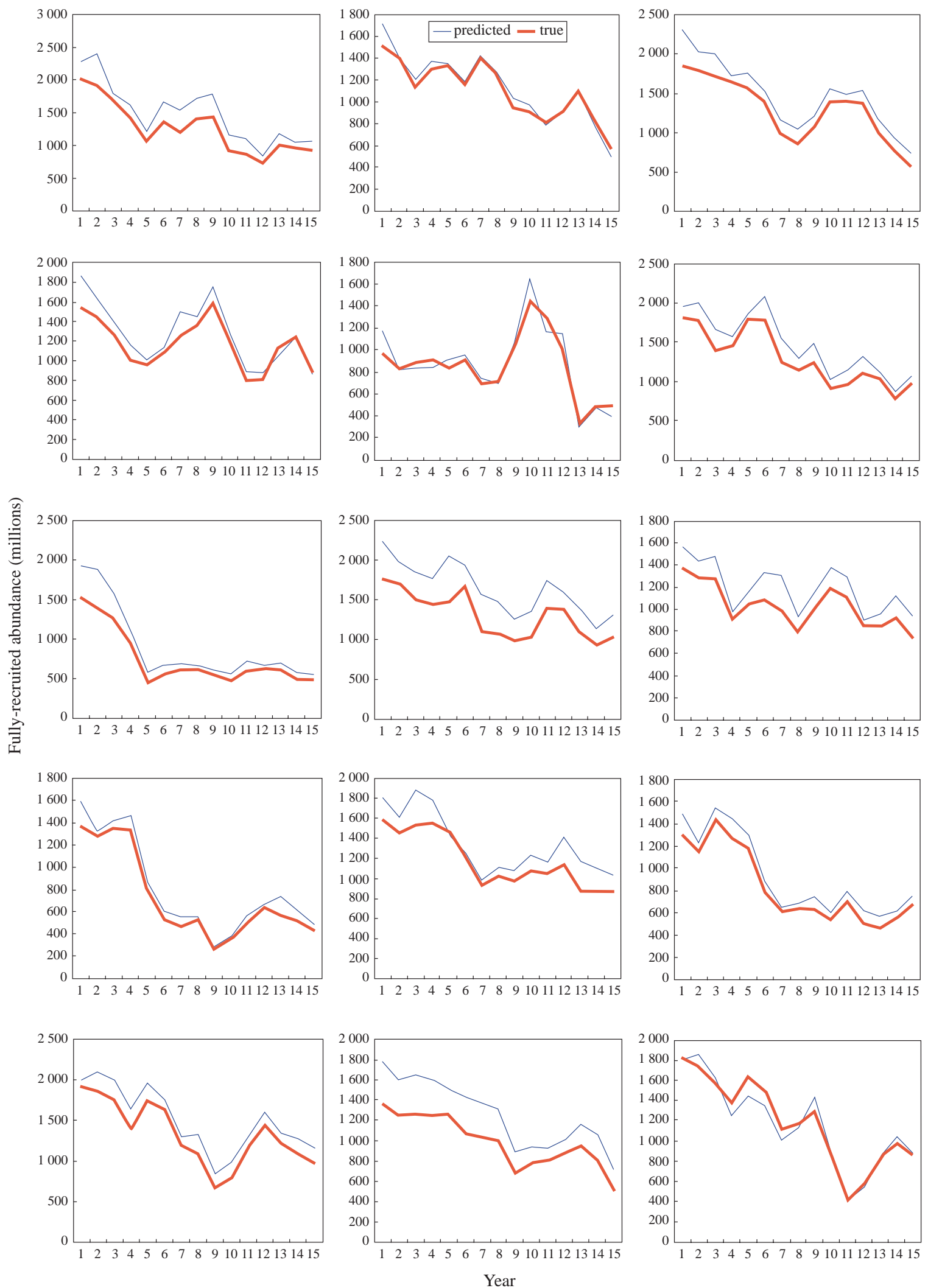

Fig. 6. True values and Catch-Survey estimates of fully-recruited abundance based on simulated shrimp-like data with specification error. Each panel represents a different simulation. 

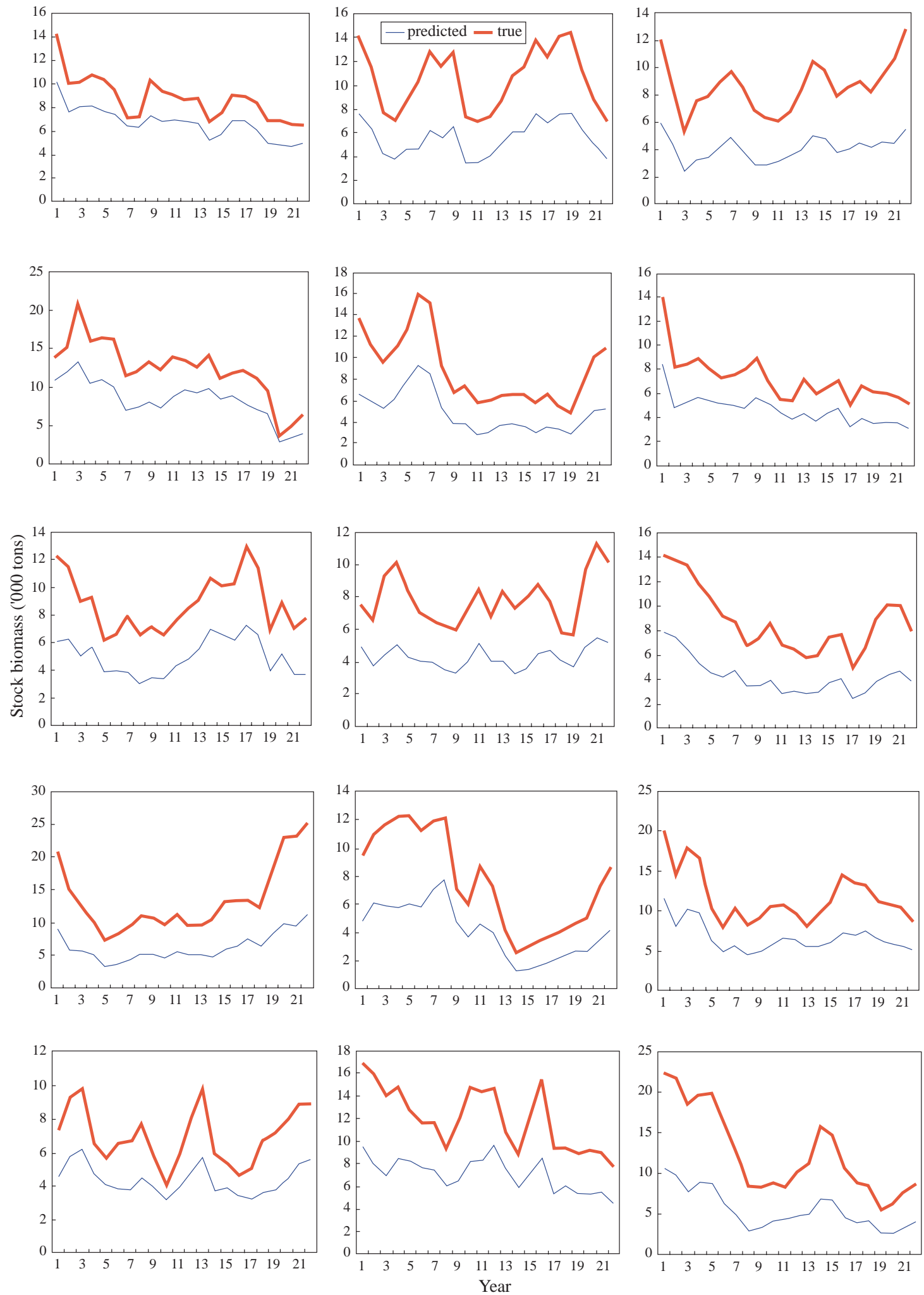

Fig. 7. True values and ASPIC estimates of stock biomass based on simulated shrimp-like data with specification error. Each panel represents a different simulation. 
a specific application should be a routine method for evaluating stock assessment methods.

\section{Acknowledgments}

I am grateful to Mike Prager for providing and supporting ASPIC software and his continued guidance. Steve Clark, Steve Murawski, Fred Serchuk, and three anonymous reviewers provided helpful suggestions on the manuscript. This study also benefitted from discussions with Han-Lin Lai, Jim Weinberg, and Larry Jacobson.

\section{References}

BREEN, P. A., and T. H. KENDRICK. 1998. An evaluation of surplus production analysis for assessing the fishery for New Zealand red rock lobsters (Jasus edwardsii). Can. Spec. Pub. Fish. Aquat. Sci., 125: 213-223.

CADRIN, S. X., S. H. CLARK, D. SCHICK, D. MCCARRON, and M. P. ARMSTRONG. 1999. Application of catch-survey models to the northern shrimp fishery in the Gulf of Maine. N. Am. J. Fish. Man. 19: 551-568.

CADRIN, S. X., and E. M. C. HATFIELD. MS 1999. Stock assessment of inshore longfin squid Loligo pealeii. NEFSC Ref. Doc., No. 99-12.

CADRIN, S. X., D.F. SCHICK, D. MCCARRON, S.H. CLARK, M.P. ARMSTRONG, B. SMITH, and J.B. O'GORMAN. MS 1998. Gulf of Maine northern shrimp stock assessment. NEFSC Ref. Doc., No. 98-07.

CADRIN, S. X., and U. SKÚLADÓTTIR. MS 1998. Surplus production analysis of shrimp in the Denmark Strait, 1977-1998. NAFO SCR Doc., No. 117, Serial No. N4026, $21 \mathrm{p}$.

CLARK, S. H., S. X. CADRIN, D. SCHICK, P. DIODATI, M. ARMSTRONG, and D. MCCARRON. 2000. The Gulf of Maine northern shrimp fishery - a review of the record. J Northw. Atl. Sci., 27: 193-226 (this volume).

COLLIE, J. S., and G. H. KRUSE. 1998. Estimating king crab (Paralithodes camtschaticus) abundance from commercial catch and research survey data. Can. Spec. Pub. Fish. Aquat. Sci., 125: 73-83.

COLLIE, J. S., and M. P. SISSENWINE. 1983. Estimating population size from relative abundance data measured with error. Can. J. Fish. Aquat. Sci., 40: 1871-1879.

CONSER, R. J., and J. IDOINE. MS 1992. A modified DeLury model for estimating mortality rates and stock sizes of American lobster populations. NEFSC Ref. Doc., No. 92-07: appendix.

GRAHAM, M. 1935. Modern theory of exploiting a fishery and application to North Sea trawling. ICES J. Cons., 10: 264-274.

HAYNES, E. B., and R. L. WIGLEY. 1969. Biology of the northern shrimp, Pandalus borealis, in the Gulf of Maine. Trans. Am. Fish. Soc., 98: 60-76.

HILBORN, R., and C. J. WALTERS. 1992. Quantitative fisheries stock assessment: choice, dynamics, and uncertainty. Chapman and Hall, NY. 570 p.

HVINGEL, C., and L. SAVARD. 1997. Northern shrimp research in the North Atlantic - state of the art and future research strategy. TemaNord, 1997: 592.

HVINGEL, C., and M. C. S. KINGSLEY. MS 1998. Jackknifing a logistic model of biomass dynamics of the West Greenland shrimp stock. NAFO SCR Doc., No. 116, Serial No. N4025, 4 p.

LUDWIG, D., C. J. WALTER, and C. J. COOKE. 1988. Comparison of two models and two estimation methods for catch and effort data. Nat. Res. Modeling, 2: 457498.

MANLY, B. F. J. 1997. Randomization, Bootstrap and Monte Carlo Methods in Biology. Chapman and Hall, London. $399 \mathrm{p}$.

MCINNES, D. 1986. Interstate fishery management plan for the northern shrimp (Pandalus borealis Kroyer) fishery in the western Gulf of Maine. ASMFC, Fish. Manag. Rep., 9, Washington, DC.

NEFSC (NORTHEAST FISHERIES SCIENCE CENTER). MS 1996. Surfclam and ocean quahog. In: $22^{\text {nd }}$ Northeast Regional Stock Assessment Workshop (22 nd SAW). NEFSC Ref. Doc., 96-13: 173-242.

NEFSC (NORTHEAST FISHERIES SCIENCE CENTER). MS 1997. Sea Scallop. In: $23^{\text {rd }}$ Northeast Regional Stock Assessment Workshop (23 $\left.{ }^{\text {rd }} \mathrm{SAW}\right)$. NEFSC Ref. Doc., 97-05: 65-152.

NRC (NATIONAL RESEARCH COUNCIL). 1998. Improving Fish Stock Assessments. National Academy Press, Washington, D.C. 177 p.

PELLA, J. J., and P. K. TOMLINSON. 1969. A generalized stock production model. Bull. Inter-Am. Trop. Tuna Comm., 13: 419-496.

POLACHEK, T., R. HILBORN, and A. E. PUNT. 1993. Fitting surplus production models: comparing methods and measuring uncertainty. Can. J. Fish. Aquat. Sci., 50: 2597-2607.

PRAGER, M. H. 1994. A suite of extensions to a nonequilibrium surplus-production model. Fish. Bull., 92: 374-389.

PRAGER, M. H. MS 1995. Users manual for ASPIC: a stock-production model incorporating covariates. SEFSC Miami Lab Doc., MIA-92/93-55.

PRAGER, M. H. 1998. Results from fitting a stockproduction model to the NRC simulated data sets. In: Analyses of simulated data sets in support of the NRC study on stock assessment methods, V.R. Restrepo, (ed.). NOAA Tech. Mem., NMFS-F/SPO-30.

PRAGER, M. H., C. P. GOODYEAR, and G. P. SCOTT. 1996. Application of a surplus production model to a swordfish-like simulated stock with time-changing gear selectivity. Trans. Am. Fish. Soc., 125: 729-740.

SCHICK, D. F., and M. BROWN. 1997. Selectivity of northern shrimp trawls. Maine Dep. Mar. Res. Compl. Rep., Project 93-NER-035, West Boothbay Harbor.

SCHNUTE, J. 1987. A general fishery model for a sizestructured fish population. Can. J. Fish. Aquat. Sci., 44: 924-940.

SCHAEFER, M. B. 1954. Some aspects of the dynamics of 
populations important to the management of commercial marine fisheries. Bull. Inter-Am. Trop. Tuna Comm., 1: 27-56.

SISSENWINE, M. P. 1977. The effect of random fluctuations on a hypothetical fishery. ICNAF Sel. Pap., 2: 137-144.

SKÚLADÓTTIR, U. 1979. Comparing several methods of assessing the maximum sustainable yield of Pandalus borealis in Arnarfjöpur. ICES Rapp. Proc.-Verb., 175: 240-252.

SKÚLADÓTTIR, U. MS 1985. The sustainable yield of Pandalus borealis in the Denmark Strait area. NAFO
SCR Doc., No. 15, Serial No. N949, 4 p.

SOKAL, R. R., and F. J. ROHLF. 1995. Biometry. W. H. Freeman and Company, New York. 887 p.

STEFÁNSSON, G., U. SKÚLADÓTTIR, and G. PÉTURSSON. 1994. The use of a stock production type model in evaluating the offshore Pandalus borealis stock of north Icelandic waters, including the predation of northern shrimp by cod. ICES C. M. Doc., No. K:25.

XIAO, Y. 1997. Subtleties in, and practical problems with, the use of production models in fish stock assessment. Fish. Res., 33: 17-36. 


\section{Appendix I}

\section{Simulated observation error}

Twenty sets of observed abundance and biomass indices were generated by randomly sampling lognormally distributed measurement errors assuming a $10 \%$ coefficient of variation $(\mathrm{CV})$ around the observed survey and catch values reported by Clark et al. (2000):

$$
\begin{gathered}
n_{t}^{\prime}=q_{n} N_{t} e^{\epsilon} \\
r_{t}^{\prime}=s_{r} q_{n} R_{t} e^{\epsilon} \\
b_{t}^{\prime}=q B_{t} e^{\epsilon}
\end{gathered}
$$

where $q_{n}$ was 0.5 and $s_{r}$ was 0.9 .

Error in observed catch (in numbers) and yield (in weight) was sampled from a normal distribution with a mean of zero and a standard deviation of $50 \mathrm{mt}$ (approximately 10\% of observed catch):

$$
\begin{gathered}
C_{t}^{\prime}=C_{t}+\epsilon \\
Y_{t}^{\prime}=Y_{t}+\epsilon
\end{gathered}
$$

\section{Simulated process error}

A fifteen-year time series of survey indices and catches was generated using the $\mathrm{C}-\mathrm{S}$ process equation (equation 6) with random errors in $M$ and $s_{r}$. In the first two years, recruitment to the fishery was sampled from a lognormal distribution with a mean of 800 million and a CV of 50\%. Fully-recruited abundance in the first year was sampled from a lognormal distribution with a mean of one billion and a CV of $50 \%$. A time series of $F$ was sampled from a lognormal distribution with a mean of 0.5 and a $\mathrm{CV}$ of $50 \%$. A time series of observed catch was generated with a series of different precisions $(10 \%, 20 \%, 30 \%, 40 \%$, and $50 \% \mathrm{CV})$ :

$$
C_{t}^{\prime}=F_{t}^{\prime}\left(N_{t}^{\prime}+0.5 R_{t}^{\prime}\right)\left[1-e^{(-F-M)}\right] /(M+F)+\epsilon
$$

Recruitment in years 3-15 was simulated as a linear function of lagged fully-recruited abundance (from Cadrin et al., 1998) with 50\% CV around the predicted value:

$$
R_{t}^{\prime}=N_{t-2}{ }^{\prime} \times 0.7 \times e^{\epsilon}
$$

Fully-recruited abundance in years $2-15$ was generated with the $\mathrm{C}-\mathrm{S}$ process equation and a $\mathrm{CV}$ of $50 \%$.

$$
N_{t+1}{ }^{\prime}=\left[\left(N_{t}^{\prime}+R_{t}^{\prime}{ }^{\prime} s_{r}^{\prime}\right) e^{-0.5 M^{\prime}}-q_{n} C_{t}^{\prime}\right] e^{-0.5 M^{\prime}} \cdot e^{\epsilon}
$$

Catchability of fully-recruited shrimp $\left(q_{n}\right)$ was assumed to be 0.5 , and $s_{r}^{\prime}$ was normally distributed with a mean of 0.9 and a $10 \% \mathrm{CV}$. Stochastic natural mortality $\left(M^{\prime}\right)$ was normally distributed with a mean of 0.25 and a $10 \% \mathrm{CV}$, excluding negative values. Time series of observed abundance indices were simulated at different precisions $(10 \%, 20 \%, 30 \%, 40 \%$, and $50 \% \mathrm{CV})$ as in equations 8 and 9 .

For surplus production analyses, 30-year time series of survey indices and catches were generated using the logistic growth equation with random errors in the parameters $r$ and $K$. Stock biomass in the first year was sampled from a distribution with a mean of $10000 \mathrm{mt}$ and a CV of $50 \%$. Yield was calculated from simulated biomass and $F$, which was sampled from a lognormal distribution with a mean of 0.5 and a CV of $50 \%$. Total biomass in years $2-30$ was simulated with the biomass dynamics process equation:

$$
B_{t+1}{ }^{\prime}=r^{\prime} B_{t}{ }^{\prime}-\left(r^{\prime} / K^{\prime}\right) B^{2}{ }_{t}^{\prime}-Y_{t^{\prime}}
$$


Catchability was assumed to be $0.5, r^{\prime}$ was distributed normally with a mean of 1.0 and a $10 \% \mathrm{CV}$, and $K^{\prime}$ was distributed normally with a mean of $20000 \mathrm{mt}$ and a $10 \% \mathrm{CV}$. A time series of observed biomass indices were simulated as in equation 10 with a $\mathrm{CV}$ of $10 \%$.

\section{Simulated model specification error}

Abundance of age- 0 shrimp in the first year of the simulation was sampled from a lognormal distribution with a mean of 2 billion and a CV of $10 \%$. Abundance of older ages $\left(N_{2}\right.$ to $\left.N_{7}\right)$ in the first year were calculated as:

$$
N_{a+1}=N_{a} e^{-(M+p F)}
$$

and $F$ in each year was sampled from a lognormal distribution with a mean of 0.5 and a $C V$ of $50 \%$. Partial recruitment-at-age $(p)$ was a function of predicted length $(L)$-at-age (from Schick and Brown, 1997):

$$
p=1 /\left[1+e^{(6.75-0.3007 L)}\right]
$$

Length-at-age in the first year was derived directly from a von Bertalanffy growth function (McInnes, 1986).

Recruitment in subsequent years was derived as a function of female biomass ( $S S B$, the product of abundanceat-age, proportion female-at-age, and weight-at-age) in the previous year:

$$
N_{0, t+1}=S S B /(0.0003 S S B+3) \times e^{\epsilon}
$$

where $\epsilon$ was sampled from a normal distribution with a mean of zero and a $10 \% \mathrm{CV}$. Weight-at-age was derived from estimated length-at-age and weight-at-length (Haynes and Wigley, 1969). Proportion female $(P)$ at age was based on observed proportion female at length (Cadrin et al., 1999):

$$
P=1 /\left[1+e^{(34.95-1.384 L)}\right]
$$

Abundance at older ages in years $2-40$ were calculated as:

$$
N_{a+1, t+l}=N_{a, t} e^{-(M+p F)}
$$

In years 2-40, $p$-at-age was based on predicted length-at-age (McInnes, 1986), reduced as a function of stock abundance in the previous year to account for slower growth during periods of high abundance (Clark et al., 2000):

$$
L_{a, t}=35.2\left(1-a e^{-0.36}\right)-0.0003 \Sigma\left(N_{a, t-1}\right)
$$

For C-S analysis, abundance of fully-recruited shrimp $(N)$ was calculated from the summed product of abundance-at-age and partial recruitment-at-age $\left[\Sigma\left(p_{a} N_{a}\right)\right]$. Abundance of recruits $(R)$ was calculated from the summed product of abundance-at-age and the difference between end-of-the-year selectivity and start-of-year selectivity-at-age $\left(\left[\Sigma\left(p_{2, a}-p_{l, a}\right) N_{a}\right]\right.$; Cadrin et al., 1999). Annual catch in numbers was calculated as:

$$
C_{t}=F_{t}\left(p_{r} R_{t}+N_{a, t}\right)\left(1-e^{-(M+F t)}\right) /\left(M+F_{t}\right)
$$

where $p_{r}$ was assumed to be 0.5 . Indices of recruit and fully-recruited abundance were simulated as described in equations 8 and 9 with CVs of $10 \%$.

For surplus production analyses, stock biomass was calculated as the summed product of abundance-at-age and mean weight-at-age. Yield in weight was calculated as the summed product of catch in number-at-age and mean weight-at-age. Indices of stock biomass were simulated as described in equation 10 with a CV of $10 \%$. 